\title{
COMPREENSÕES DE LICENCIANDOS SOBRE A SUPERAÇÃO DAS DIFICULDADES DE APRENDIZAGEM NO ENSINO FUNDAMENTAL
}

\author{
José Moysés Alves ${ }^{1}$ \\ Hanna Patrícia da Silva Bezerra² \\ Rosineide Almeida Ribeiro ${ }^{3}$
}

\begin{abstract}
RESUMO
A maneira como os professores compreendem a superação das dificuldades de aprendizagem pode contribuir para a construção de alternativas ao ensino conteudista e à medicalização do problema. No presente estudo objetivamos analisar a aprendizagem de conceitos da teoria da subjetividade sobre a superação das dificuldades de aprendizagem, por professores em formação inicial e as relações que estabelecem entre tais conceitos e observações de crianças em contexto escolar. Relatamos uma pesquisa qualitativa de tipo documental, em uma de nossas turmas, com 22 licenciandos. Analisamos o conteúdo das suas produções escritas em diferentes momentos de uma sequência didática, ao responderem questões de estudo, analisarem um filme e relatarem observações de crianças com dificuldades de aprendizagem. Os resultados indicaram que a sequência didática favoreceu a compreensão das ideias da teoria e sua articulação com a prática. Os licenciandos passaram a valorizar o diálogo, no diagnóstico e na intervenção, a singularidade do aprendiz, as dimensões afetiva e relacional na explicação da superação das dificuldades de aprendizagem. Suas concepções anteriores, no entanto, dificultaram a compreensão das noções teóricas, indicando que a mudança conceitual precisa acontecer nos níveis epistemológico, ontológico e conceitual.
\end{abstract}

Palavras-chave: formação inicial; teoria da subjetividade; superação das dificuldades de aprendizagem.

\section{UNDERGRADUATE STUDENTS' COMPREHENSIONS OF OVERCOMING} LEARNING DIFFICULTIES IN ELEMENTARY SCHOOL

\begin{abstract}
The way teachers understand overcoming learning difficulties can contribute to the construction of alternatives to content teaching and medicalization of the problem. In the present study, we aim to analyze the learning of concepts from the theory of subjectivity on overcoming learning difficulties, by teachers in initial training and the relationships they establish between such concepts and observations of children in a school context. We report a qualitative research of documentary type, in one of our classes, with 22 graduates. We analyzed the content of the graduates' written productions at different times in a didactic sequence, when answering study questions, analyzing a film and reporting observations of children with learning difficulties. The results indicated that the didactic sequence favored the understanding of the ideas of the theory and its articulation with the practice. The undergraduate students started to value dialogue, in diagnosis and intervention, the uniqueness of the learner, the affective and relational dimensions in explaining overcoming learning difficulties. However, his previous conceptions made it difficult to understand theoretical notions, indicating that conceptual change needs to happen at the epistemological, ontological and conceptual levels.
\end{abstract}

Keywords: initial training; theory of subjectivity; overcoming learning difficulties.

Recebido em: $15 / 6 / 2020$

Aceito em: $16 / 7 / 2020$

\footnotetext{
1 Autor correspondente. Universidade Federal do Pará - Instituto de Educação Matemática e Científica (lemci/Ufpa). R. Augusto Corrêa, 1 - Guamá. Belém/PA, Brasil. CEP 66075-110. http://lattes.cnpq.br/6500775506186127. http://orcid.org/0000-0003-1307-1249. jmalves@ ufpa.br.

2 Instituto Federal do Amapá (Ifap). Santana/AP, Brasil. http://lattes.cnpq.br/1403519476288619. http://orcid.org/000-0002-5723-9069.

3 Universidade Federal do Pará (Ufpa). Belém/PA, Brasil. http://lattes.cnpq.br/7251850038595402. http://orcid.org/0000-0002-5110-6820.
} 


\section{INTRODUÇÃO}

Este artigo relata uma pesquisa sobre a própria prática (ANDRÉ, 2016; LÜDKE, 2001) de um professor e duas doutorandas, que realizaram estágio em docência no Ensino Superior. $O$ estudo foi desenvolvido com uma turma de licenciandos do curso de Licenciatura em Educação em Ciências, Matemática e Linguagens (LIECML), da Universidade Federal do Pará (Ufpa), no tema Compreensão e Explicação dos Processos de Desenvolvimento e Aprendizagem II (Cepad II). Neste trabalho analisamos a aprendizagem dos licenciandos, em uma sequência didática sobre superação das dificuldades de aprendizagem, um dos assuntos que estudamos no referido tema.

A relação entre os conteúdos pedagógicos, ensinados nos cursos de Licenciatura, e a atuação profissional dos (futuros) professores têm preocupado pesquisadores da área. Em geral, tais conteúdos não são ensinados de modo a facilitar sua articulação com a prática profissional (GATTI, 2010, 2013; MITJÁNS MARTíNEZ; GONZÁLEZ REY, 2017).

Segundo Gatti et al. (2019, p. 195), algumas questões persistem no campo da formação docente, entre elas:

Que tipos de atividades formativas têm potencial para favorecer o desenvolvimento dos conhecimentos profissionais? Como formar, simultaneamente, profissionais reflexivos, com postura investigativa e capazes de analisar e de teorizar sobre as suas práticas? Que aspectos devem ser considerados na avaliação das práticas formativas?

Tais preocupações têm nos mobilizado, ultimamente, em nosso ofício de ensinar conhecimentos de Psicologia para licenciandos e a realizar investigações sobre estas práticas, na perspectiva de aperfeiçoá-las (ALVES; PARENTE, 2020; PARENTE; ALVES, 2020).

Os conhecimentos psicológicos sobre desenvolvimento e aprendizagem, comumente ensinados nas Licenciaturas, ao enfatizarem o desenvolvimento cognitivo, não contribuem no sentido de gerar alternativas ao ensino conteudista e padronizado, que favorece o surgimento das dificuldades de aprendizagem. Em oposição a esta tendência, a teoria da subjetividade destaca a singularidade do sujeito que aprende, concebendo a natureza, simultaneamente, social-individual e simbólico-emocional da constituição processual de sua subjetividade (GONZÁLEZ REY, 2006; MITJÁNS MARTÍNEZ; GONZÁLEZ REY, 2017).

De acordo com esse referencial, sentidos subjetivos são unidades simbólico-emocionais da subjetividade, que se organizam em configurações subjetivas, simultânea e processualmente, na personalidade e nos contextos sociais dos quais o indivíduo participa. As configurações mais estáveis fazem parte da personalidade ou subjetividade individual e são o ponto de partida para a produção de sentidos subjetivos pelo sujeito, durante sua ação, que também depende dos sentidos associados à subjetividade social e aos sistemas relacionais dentro dos quais tal ação ocorre. As configurações subjetivas da ação são menos estáveis e podem ou não passar a fazer parte das configurações subjetivas da personalidade em desenvolvimento (MITJÁNS MARTíNEZ; GONZÁLEZ REY, 2017). 
Para ir além da aprendizagem reprodutiva-memorística e aprender de forma compreensiva, personalizando as informações recebidas, ou criativamente, gerando a partir dessa compreensão, ideias novas, o aprendiz produz sentidos subjetivos. Tais sentidos podem passar a constituir seu desenvolvimento subjetivo individual e contribuir para o desenvolvimento dos espaços sociais dos quais ele participa (MITJÁNS MARTíNEZ; GONZÁLEZ REY, 2017).

Uma mudança significativa acontece na prática pedagógica quando, em lugar da ênfase tão comum no conteúdo, passamos a valorizar o sujeito que aprende e suas relações sociais. O professor dedica-se a investigar as necessidades e as formas de aprender dos aprendizes (TACCA, 2009). Pensa estratégias pedagógicas, não como aquilo que planeja com antecedência, o que é importante, mas como o que faz, durante a interação com o aprendiz, na perspectiva de conhecer suas motivações, emoções, formas de pensar e para entrar em sintonia de pensamento com ele, o que é ainda mais importante (TACCA, 2006).

A consideração da singularidade das crianças que apresentam dificuldades de aprendizagem, da complexidade de suas relações sociais e dos sentidos subjetivos que produzem diante de tais relações, tem possibilitado pesquisadores, orientados pela teoria da subjetividade, ajudar estas crianças e as pessoas que cuidam delas e as educam, a superarem suas dificuldades (ROSSATO; MITJÁNS MARTÍNEZ, 2011). Fazendo assim, os pesquisadores oferecem uma alternativa à tendência, comumente observada nas escolas, de responsabilizar a criança e sua família por suas dificuldades de aprendizagem e de abordar o problema pela perspectiva médica, muitas vezes pouco promissora para o desenvolvimento da criança.

A superação das dificuldades de aprendizagem tornou-se uma linha de pesquisa promissora dentro da teoria da subjetividade. Muitas pesquisas foram realizadas, com bons resultados práticos e desenvolvendo um modelo teórico de grande valor heurístico (BEZERRA, 2014; MEDEIROS, 2018; ROSSATO; MITJÁNS MARTíNEZ, 2011).

A partir deste referencial teórico entende-se que as dificuldades de aprendizagem, com ou sem deficiências de natureza biológica associadas, acontecem quando um sujeito é negado, quando ele produz sentidos subjetivos que são desfavoráveis à aprendizagem e quando estão presentes configurações subjetivas geradoras de danos. Este conhecimento depende de um diagnóstico abrangente, envolvendo a compreensão da maneira como o aprendiz é subjetivado pelos outros que se relacionam com ele e a maneira como ele subjetiva os diversos contextos sociais de que participa (ROSSATO; MITJÁNS MARTÍNEZ, 2011).

A superação de tais dificuldades, por sua vez, depende de uma intervenção do pesquisador, que a partir do diagnóstico da situação recomenda mudanças no tratamento dispensado à criança, principalmente por seus familiares e pela professora, além dos diálogos que mantém com a própria criança. A superação das dificuldades de aprendizagem acontece quando o sujeito passa a ser (e a se sentir) valorizado, quando volta a produzir sentidos favoráveis à aprendizagem e ocorrem mudanças em suas configurações subjetivas geradoras de dano (ROSSATO; MITJÁNS MARTíNEZ, 2011). 
Diante do exposto, consideramos relevante que os licenciandos aprendam, entre outros conhecimentos psicológicos, os conceitos da teoria da subjetividade, articulados com temas importantes de sua formação profissional, entre eles a superação das dificuldades de aprendizagem. Assim, nesta investigação, nosso foco foi a compreensão dos licenciandos sobre a superação das dificuldades de aprendizagem à luz da teoria da subjetividade, mais especificamente, as relações que estabeleceram entre os conceitos da teoria e destes com observações de crianças com dificuldades de aprendizagem em contexto escolar.

\section{MÉTODO}

Participaram da pesquisa 22 licenciandos, 5 homens e 17 mulheres, de uma turma do tema Cepad II da LIECML da Ufpa. Para preservar o anonimato dos participantes não revelamos o ano em que ocorreram as aulas nem os seus nomes. Entre outros temas, os licenciandos realizaram estágio no mesmo semestre do tema Cepad II.

O tema Cepad II tem carga horária total de 60 horas. No semestre em que realizamos a pesquisa optamos por não apresentar aos licenciandos textos que discutissem, exclusivamente, os conceitos da teoria da subjetividade. Selecionamos quatro capítulos de livros, todos dentro do referido referencial teórico, abordando assuntos específicos relacionados à prática profissional do professor. Planejamos três sequências didáticas, uma delas sobre a superação das dificuldades de aprendizagem, outra sobre estratégias pedagógicas e a última sobre criatividade na aprendizagem e na prática pedagógica.

A sequência didática sobre superação das dificuldades de aprendizagem, analisada no presente artigo, foi realizada em seis aulas de quatro horas cada. Na primeira aula conversamos sobre as compreensões de subjetividade dos licenciandos. Na segunda e na terceira realizamos leituras e discutimos os textos: $O$ professor investigador: criando possibilidades para novas concepções e práticas sobre ensinar e aprender (TACCA, 2009) e A Superação das Dificuldades de Aprendizagem e as Mudanças na Subjetividade (ROSSATO; MITJÁNS MARTÍNEZ, 2011). Na quarta aula assistimos ao filme Como Estrelas na Terra - Toda criança é especial (KHAN, 2007). Na quinta discutimos uma análise sobre a superação das dificuldades de aprendizagem do personagem do filme feita pelos licenciandos, relacionando com os textos lidos. Na sexta e última aula desta sequência os licenciandos apresentaram, em Power point, seminários para a turma, relatando observações de crianças com dificuldades de aprendizagem, feitas no contexto do estágio que estavam realizando. Também foram solicitados a estabelecer relações entre estas observações e os textos lidos.

Em cada etapa da sequência os estagiários realizaram produções escritas, que subsidiaram discussões com a turma. Eles responderam, por escrito, questões de estudo sobre os textos. Também abordaram a análise sobre a emergência e a superação da dificuldade de aprendizagem do personagem do filme. Escreveram ainda o relato sobre algumas de suas observações de estágio, envolvendo crianças com dificuldades de aprendizagem. 
Recebemos respostas escritas às questões de estudo do primeiro texto de nove duplas e quatro licenciandos, individualmente. No segundo texto recolhemos as respostas escritas de dez duplas. A análise do filme foi feita individualmente por oito licenciandos e sete duplas. Um dos relatos do estágio foi feito por um trio de estudantes que realizavam o estágio na mesma turma, os demais foram produzidos por oito duplas.

Apesar de ser um estudo sobre a aprendizagem de conceitos da Teoria da Subjetividade, a presente pesquisa não é uma investigação da dimensão subjetiva da aprendizagem dos licenciandos nem é inspirada nos princípios da Epistemologia Qualitativa (MITJÁNS MARTíNEZ, 2019). Não analisamos a produção de sentidos subjetivos pelos licenciandos, mas os significados que eles elaboraram, que indicam aprendizagens dos conceitos da teoria e sua articulação com situações práticas (ficcionais ou reais), dentro de uma sequência didática.

Inspirados na pesquisa qualitativa de tipo documental (ESTEBAN, 2010; KRIPKA; SCHELLER; BONOTTO, 2015) pretendemos compreender em profundidade a elaboração conceitual feita pelos licenciandos, na perspectiva de reformular nossa prática de ensino. Partimos da própria linguagem dos participantes, tomando suas produções escritas como documentos, que testemunham a forma que conseguiam elaborar por escrito o que pensavam em cada etapa da sequência didática.

Após várias leituras, selecionamos deste material aqueles que consideramos mais informativos para os nossos objetivos de pesquisa e realizamos uma análise de conteúdo (KRIPKA; SCHELLER; BONOTTO, 2015). Escolhemos para análise três das questões de estudo, uma do primeiro texto (O que os professores precisam fazer para ter mais sucesso em suas intervenções com estudantes que apresentam dificuldades de aprendizagem?) e duas do segundo texto (Conceitualmente, o que gera as dificuldades de aprendizagem escolar? e Qual o modelo teórico que as autoras elaboraram para explicar a superação das dificuldades de aprendizagem?). Também analisamos o exercício de análise do filme e os relatos de observações do estágio.

$\mathrm{Na}$ análise do conteúdo das produções escritas agrupamos tais produções em categorias que expressavam diferenças na compreensão dos textos e na relação dessas ideias com a prática. Também fizemos uma quantificação simples dos trabalhos dos licenciandos, que classificamos em cada categoria. llustramos cada uma com exemplos das produções escritas e comentamos, sobre tais exemplos, aspectos relacionados à aprendizagem dos licenciandos, apontando avanços e dificuldades nesse processo.

\section{RESULTADOS}

Na primeira aula, entre outras conversas sobre o tema, pedimos aos licenciandos que registrassem por escrito o que entendiam por subjetividade. A análise das respostas indicou que suas concepções iniciais sobre subjetividade se distanciavam, em alguns aspectos, da visão da teoria da subjetividade que pretendíamos lhes ensinar. Eles pensavam subjetividade como algo individual, interno, que não é objetivo e que é determinado biológica e/ou socialmente.

Teoricamente, a subjetividade é concebida por González Rey e Mitjáns Martínez (2017, p. 27) como 
um sistema simbólico-emocional orientado à criação de uma realidade peculiarmente humana, a cultura, da qual a própria subjetividade é condição de seu desenvolvimento e dentro da qual tem a sua própria gênese, socialmente institucionalizada e historicamente situada.

Nesta perspectiva supera-se as dicotomias individual-social, interno-externo, objetivo-subjetivo e a subjetividade não é pensada como reflexo de uma realidade social, externa ao sujeito.

\section{Compreensão de ideias dos textos}

para a segunda aula solicitamos que os licenciandos lessem o capítulo de Tacca (2009) e Ihes entregamos oito questões de estudo a serem respondidas por escrito. A questão de estudo do texto que selecionamos para análise foi: "O que os professores precisam fazer para ter mais sucesso em suas intervenções com estudantes que apresentam dificuldades de aprendizagem?"

Agrupamos as 14 respostas dos licenciandos nas seguintes categorias: 1) menciona realizar o diagnóstico, indicando como (9 respostas), 2) menciona apenas realizar o diagnóstico (3 respostas) e 3) não capta a ideia central do texto (2 respostas).

Transcrevemos, a seguir, uma resposta agrupada na categoria 3. Além de não captar a ideia central do texto, indica a compreensão de que é suficiente o professor escoIher atividades diferenciadas, que seu ensino será bem-sucedido. Representa, para nós, uma visão determinista, unidirecional, do ensino sobre a aprendizagem: "Atividades selecionadas, diferenciadas, pensadas com base em materiais especiais e incorporando a ludicidade, tornando assim as atividades mais significativas e prazerosas" (Resposta - Estudantes A e M).

De forma diferente, em uma das respostas agrupadas na categoria 2, a seguir, consideramos que o licenciando captou a ideia central do texto, ainda que não tenha aproveitado as ideias da autora sobre como o professor pode fazer seu diagnóstico e intervenção: "O texto aponta a investigação e a compreensão do processo de aprendizagem de cada aluno como principal fonte para o desenvolvimento de práticas pedagógicas que alcancem esses alunos" (Resposta - Estudante M).

Na resposta transcrita, a seguir, agrupada na categoria 1, além de captar a ideia central do texto, os licenciandos aproveitaram ideias sobre como deve ser feito o diagnóstico e a intervenção nas dificuldades de aprendizagem:

Primeiramente o profissional precisa ter clareza sobre as expectativas de aprendizagem de cada aluno. É papel do docente fazer o acompanhamento das crianças individualmente, durante todo o período, para se certificar que os alunos estão de fato aprendendo. Logo após esse acompanhamento, poderá avaliar qual a melhor estratégia para conduzir cada caso e traçar um plano de ação. Para a autora, os professores precisam investigar a produção de sentido do aluno, primordialmente daqueles que não estão aprendendo com os mesmos níveis que os outros. Terá que ser um investigador de sua própria prática, a partir desse processo de conhecer o aluno, ele poderá encaminhar suas práticas, deixando de lado as avaliações isoladas e acompanhar os processos de produção de sentidos dentro da realização do sujeito. $O$ professor deverá ir colocando desafios para que nessa problematiza- 
ção, possa acompanhar o desenvolvimento do aluno, permitindo tirar a ideia sobre a dificuldade dos alunos e a conclusão de resultados fragmentados que acontecem de maneira isolada (Resposta - estudantes C e V).

Notamos que mais de dois terços da turma compreenderam a ideia central do texto. Resumidamente, que o professor alcança sucesso em sua intervenção quando procura conhecer o aluno em sua singularidade subjetiva, social e individual, simbólico-emocional, ao mesmo tempo que aposta em seu potencial de aprendizagem. Segundo a autora, o diálogo com o estudante é fundamental tanto na realização do diagnóstico da dificuldade quanto na intervenção pedagógica, visando a sua superação (TACCA, 2009).

Para a terceira aula pedimos que os licenciandos lessem o capítulo de Rossato e Mitjáns Martínez (2011). Também elaboramos seis questões de estudo sobre o texto que os licenciandos deveriam responder por escrito e trazer para serem discutidas na aula. Selecionamos para análise duas das questões de estudo: "Conceitualmente, o que gera as dificuldades de aprendizagem escolar?" e "Qual o modelo teórico que as autoras elaboraram para explicar a superação das dificuldades de aprendizagem?"

Assim, para análise das 10 respostas à questão "Conceitualmente, o que gera as dificuldades de aprendizagem escolar?", agrupamos a produção escrita dos licenciandos em duas categorias: 1 ) cita corretamente o texto, sem personalizar (5 respostas); e 2) personaliza as ideias do texto de forma incorreta/inadequada (5 respostas).

Transcrevemos a seguir uma das respostas classificada na categoria 2. Interpretamos que a resposta não capta a ideia central do texto, pois explica a dificuldade como resultado de fatores genéticos ou ambientais, sem levar em conta como o sujeito é subjetivado pelos outros com quem interage e como subjetiva os contextos em que aprende: "Vários fatores podem ocasionar as dificuldades de aprendizagem, podendo ser genético ou ocasionado por outros transtornos externos, mas que sempre causam danos àquele indivíduo" (Resposta - Estudantes S e J).

Classificamos a resposta transcrita a seguir na categoria 1, pois recorta adequadamente o texto das autoras, citando-o de forma direta, sem traduzi-lo para suas palavras:

O problema das dificuldades de aprendizagem não está articulado diretamente à família, à pobreza, à relação aluno-professor ou a tantos outros na forma em que comumente são usados para justificar as dificuldades, mas na forma em que as diferentes experiências vividas pelo aprendiz são configuradas subjetivamente e presentificam-se na aprendizagem escolar (Resposta - Estudantes M e T).

Estes resultados indicam que os licenciandos tiveram dificuldades em compreender, traduzindo para suas palavras, a maneira como as autoras conceituam dificuldades de aprendizagem. Apenas em metade das respostas localizaram a definição das autoras e citaram diretamente o texto. A perspectiva das autoras supera o determinismo biológico e a ênfase nos aspectos cognitivos, a partir dos quais, normalmente, profissionais da escola diagnosticam os estudantes com dificuldades, rotulando-os como incapazes de aprender. Assim, Rossato e Mitjáns Martínez (2011) explicam que os estudantes apresentam dificuldades quando produzem sentidos subjetivos desfavoráveis ao processo de aprendizagem. Estes sentidos não estão relacionados, exclusivamente, com situações escolares, mas com as outras esferas da vida social do estudante. 
A próxima questão selecionada para análise do capítulo de Rossato e Mitjáns Martínez (2011) foi: "Qual o modelo teórico que as autoras elaboraram para explicar a superação das dificuldades de aprendizagem?"

Para a análise, classificamos as 10 produções escritas dos licenciandos nas categorias: 1) faz referência ao modelo, sem descrevê-lo (5 respostas) e 2) não faz referência ao modelo de forma adequada (5 respostas).

Nas respostas agrupadas na categoria 2 interpretamos que os licenciandos compreenderam que deveriam responder qual era o modelo teórico geral ("teoria da subjetividade", uma das respostas) ou de que forma o modelo teórico é construído, como na seguinte resposta: "A elaboração do modelo teórico se dá por meio de formulação de hipóteses que podem ser construídas e desconstruídas constantemente" (Resposta - Estudantes J e A).

A seguir transcrevemos uma das respostas que agrupamos na categoria 1, em que é feita uma referência ao modelo, mas sem descrevê-lo:

A partir da hipótese da teoria da subjetividade, que interpreta como a subjetividade afeta diretamente no ensino-aprendizagem, as autoras identificam o reconhecimento da subjetividade como um dos principais fatores a serem trabalhados para superação das dificuldades de aprendizagem (Resposta - Estudantes B e M).

$\mathrm{Na}$ análise das respostas às duas questões deste texto, constatamos certa dificuldade dos licenciandos de compreenderem as dificuldades de aprendizagem e sua superação, nos termos da teoria da subjetividade. Na primeira, metade da turma não apresentou uma resposta adequada sobre a definição de dificuldade de aprendizagem, centrando os comentários numa compreensão determinista da dificuldade, ocasionada por fatores biológicos e/ou sociais. A outra metade da turma apresentou citações do texto, não ocorrendo personalização das respostas.

Novamente estes resultados indicam que os licenciandos tiveram dificuldade para compreender, em sua primeira leitura, a explicação das autoras para a emergência das dificuldades de aprendizagem e sua superação. A partir deste referencial teórico a negação do sujeito, o fato dele produzir sentidos subjetivos desfavoráveis à aprendizagem e a presença de configurações subjetivas geradoras de danos são fatores que explicam a emergência das dificuldades de aprendizagem (ROSSATO; MITJÁNS MARTÍNEZ, 2011).

Considerando a análise destas respostas e das obtidas em momentos anteriores, conjecturamos que as dificuldades dos licenciandos não foram tanto de aprender conceitos específicos. Inspirados em Pozo e Crespo (2009), consideramos que suas dificuldades se devem ao fato de suas teorias psicológicas implícitas diferirem, epistemológica, ontológica e conceitualmente, das ideias da teoria da subjetividade. Voltaremos a esta discussão em nossas considerações finais.

\section{Relações entre ideias dos textos e análises do filme}

Como referimos anteriormente, todas as questões foram discutidas com os licenciandos em sala de aula e, para o encontro seguinte, planejamos assistir ao filme Como estrelas na terra - Toda criança é especial, do diretor indiano Aamir Khan. Os licenciandos deveriam reler o texto, assistir ao filme e fazer anotações, retirando dele informa- 
ções para a análise do caso do menino Ishaan Awasthi, protagonista do filme, de acordo com o modelo proposto por Rossato e Mitjáns Martínez (2011) sobre a superação das dificuldades de aprendizagem.

$\mathrm{Na}$ quarta aula assistimos ao filme em sala. Muitos se emocionaram durante a apresentação e, posteriormente, elogiaram o filme, nos indicando que esta foi uma condição favorecedora da produção de sentidos subjetivos por parte dos licenciandos, especialmente relacionados ao ensinar e ser educador.

$\mathrm{Na}$ aula seguinte eles trouxeram suas análises do filme, por escrito. Foram produzidos 16 textos. Destes, 8 explicitaram relações com o texto de Rossato e Mitjáns Martínez (2011), de acordo com nossas solicitações, 2 estabeleceram relações com o texto de Tacca (2009) e uma análise citou os dois capítulos estudados. Cinco análises simplesmente descreveram o filme, sem fazer nenhuma relação explícita com os dois textos.

A necessidade de considerar a singularidade do sujeito que aprende foi uma ideia frequente nos textos dos licenciandos. Transcrevemos dois exemplos a seguir (grifos nossos):

Os professores principalmente não levaram em consideração a sua singularidade, nesse caso é notório que os docentes não consideraram o aluno como sujeito que aprende quando apontaram apenas o problema e não a solução. A autora (Tacca, 2009) destaca ainda que os diagnósticos identificam as dificuldades, porém os professores não conseguiam fazer um diagnóstico para poder elaborar uma estratégia de ensino (Trecho da análise - Estudante $\mathrm{C}$ ).

Ishaan passou a ser visto pelo professor, pela família e pela escola como um sujeito. Como alguém que tem suas dificuldades, mas que é capaz de superar cada uma delas. Como vimos no texto estudado em sala (referência ao capítulo de Rossato e Mitjáns Martínez, 2011), a superação das dificuldades de aprendizagem não é exclusivamente um processo cognitivo, mas se dá na relação complexa e sistêmica entre as diversas dimensões que perpassam a vida do aprendiz, isso envolve o biológico, subjetivo, social, cultural e histórico (Trecho da análise - Estudantes J e L).

A crença no potencial de aprendizagem dos alunos também foi um aspecto frequentemente referido nos textos dos licenciandos. A "relação complexa e sistêmica que perpassa a vida do aprendiz", que já tinha sido exemplificada com o caso de João, apresentado no texto de Rossato e Mitjáns Martínez (2011), também ganhou destaque a partir da narrativa do filme, embora em algumas análises dos licenciandos sejam apresentados como fatores biológicos e sociais justapostos, que não são compreendidos como a tensão entre configurações subjetivas individuais e sociais. Vamos apresentar outros excertos, a seguir, para analisarmos as causas que os licenciandos atribuíram à dificuldade de aprendizagem e como explicaram a sua superação.

Quanto às causas atribuídas às dificuldades de aprendizagem de Ishaan, verificamos que sete análises as atribuíram, exclusivamente, à dislexia. Seguem dois exemplos (grifos nossos): 
Em casa seu pai era muito rígido e distante, e o garoto sofria muito devido ao fato dele nunca ir bem na escola e não saber ler nem escrever, só que os professores e os pais não tinham percebido que ele tinha essas dificuldades de aprendizagem devido possuir dislexia (Trecho da análise - Estudante B).

O filme se passa na Índia, conta a história de um menino chamado Ishaan Awasthi que sofre com dificuldades de aprendizagem por questões biológicas, apresenta dislexia. Ele estuda em uma escola de ensino regular, repetiu uma vez a terceira série e corre o risco de repetir novamente. A dislexia o impossibilita de acompanhar a turma. O menino tem apenas nove anos e sofre com o despreparo de professores que aparentemente trabalham com um ensino tradicional, não focado no aluno e o convívio difícil com os colegas, por apenas observarem suas dificuldades (Trecho da análise - Estudantes A e M).

Apesar de apontarem a dislexia como a única causa da dificuldade de Ishaan, os licenciandos consideraram as dificuldades dos pais e dos professores para lidarem com o problema, que acarretava sofrimento para a criança. O sofrimento da criança é visto como resultado de toda a situação, mas não como constituinte da própria dificuldade. Os licenciandos continuam com este tipo de visão, mesmo tendo assistido no filme que Ishaan, em outro momento, apesar de sua dislexia, superou as dificuldades de aprendizagem.

Em seis análises, os licenciandos consideraram que as dificuldades de aprendizagem de Ishaan eram causadas pela dislexia e por outros fatores, como a relação com o pai, a negação da expressão do aprendiz enquanto sujeito, a incompreensão das dificuldades da criança pela família e pelas escolas em que estudou e a metodologia tradicional das aulas. Evidenciando um entendimento de justaposição entre os fatores biológicos e sociais, o estudante $M$ escreveu em sua análise (grifos nossos):

É possível notar durante o filme que a criança tem uma forma diferente de ver o mundo, o que a princípio não agrada aos adultos e as barreiras e dificuldades acabam afetando a sua aprendizagem. Além de sua forma de pensar diferente, a criança também possui dislexia, o que somada às relações que ela estabelece em cada momento de sua vida acarreta na dificuldade de aprendizagem.

Neste outro trecho o mesmo estudante afirmou: "Na perspectiva da teoria da subjetividade, tendo em Ishaan um garoto com dificuldade de aprendizagem, causada pela não identificação de sua dislexia e pelas relações sociais" (Trecho da análise - Estudante $M$, grifo nosso ). Parece que mesmo reconhecendo a importância das relações sociais, a maneira de pensar do licenciando é a da influência linear e direta do social sobre o individual. A dificuldade ainda não é compreendida como decorrente dos sentidos subjetivos que Ishaan produz nessas relações.

Três análises atribuíram as dificuldades de aprendizagem a outros fatores, como a negação do sujeito, às relações sociais com a família, com os colegas e com a escola e à incompreensão das singularidades do garoto, sem mencionar a dislexia.

Seus professores e pais não o compreendem por serem de famílias pobres e em busca de uma melhora de vida que exige dos filhos um êxito que não alcançaram, acabando os obrigando a carregar um fardo de seus desejos sendo uma das condições geradoras de danos mais terríveis, pois a família é fundamental para a evolução da criança. [...] Em sala a situação é ainda pior, pois os professores agem de 
forma padrão com todos os alunos, tratando-os da mesma forma, negando a sua subjetividade. Ishaan é uma criança extremamente sensível e que presta atenção em cada detalhe do seu cotidiano e isso foi negado a ele enquanto sujeito único e singular, pois seus professores queriam que ele aprendesse da mesma forma que ensinavam a todos (Trecho da análise - Estudantes L e L, grifos nossos).

Em relação à superação das dificuldades de aprendizagem de Ishaan, todos os textos explicitaram que foram superadas devido ao método do professor, indicando, novamente, uma visão determinista social na explicação da conduta da criança. Na maioria dos textos, contudo, os licenciandos caracterizaram o professor como investigador da singularidade do aprendiz, que o reconheceu como sujeito capaz de aprender e propôs atividades diferenciadas, de acordo com suas necessidades. $O$ trecho a seguir é um exemplo desse tipo de análise:

Fazendo referência ao que estudamos [...] um estudante que apresenta problemas de aprendizagem, necessita ser compreendido na sua totalidade, e para que a aprendizagem ocorra, é necessário promover situações pedagógicas que impactem na constituição subjetiva do aprendiz, podendo então incidir no desenvolvimento e gerar novas possibilidades de aprender [...] Sendo assim, a partir de que o professor de Artes reconheceu as dificuldade de Ishaan, ele começou a trabalhar de acordo com as suas subjetividades, ele buscou não somente focar nas suas dificuldades, mas partiu do que o garoto já sabia, para que ele pudesse gerar novos conhecimentos e superar as dificuldades. Pois, segundo os autores, o estudante que apresenta uma deficiência biológica quando inserido em boas situações de aprendizagem pode ter muito mais alternativas de desenvolvimento e de superação das dificuldades de aprendizagem (Trecho da análise - Estudante B).

Consideramos que nesta etapa avançamos na compreensão da superação das dificuldades de aprendizagem, de acordo com o referencial teórico discutido, com repercussões importantes para a formação profissional dos licenciandos. Além dos aspectos mencionados anteriormente, queremos ressaltar, por um lado, a crítica à padronização do ensino e ao conteudismo, por outro lado, a valorização das relações sociais e do diálogo. Seguem alguns exemplos (grifos nossos): "No que pudemos identificar e comparar com os inúmeros exemplos de nossa realidade, é que não era o aluno que tinha que mudar, mas o professor" (Trecho da análise - Estudantes T e G); "Muitas vezes, os professores acreditam que todos alunos aprendem da mesma maneira e se preocupam apenas com o conteúdo que têm que cumprir ao invés de se preocupar com o que o sujeito sabe e pensa" (Trecho da análise - Estudante MF); "A sua singularidade não é levada em consideração, as aulas são totalmente focadas no conteúdo a ser ministrado e sem diálogo entre professor-aluno e aluno-professor a superação das dificuldades do aluno se tornam quase que impossíveis" (Trecho da análise - Estudante MC).

Além das leituras e discussões, de nossa insistência em explicar a superação das dificuldades de aprendizagem sob a ótica da teoria da subjetividade, durante as discussões, consideramos que o estudo de caso de João, apresentado no segundo texto, e o exercício de análise do caso de Ishaan, protagonista do filme, foram condições facilitadoras da aprendizagem dos licenciandos. Em ambos os casos a complexidade das relações e das produções subjetivas que resultam na dificuldade de aprendizagem, bem como a complexidade de relações e produções subjetivas necessárias para sua supera- 
ção, foram ricamente ilustradas. As conversas sobre os casos com os licenciandos foram momentos de reflexões importantes. Além da relevância dos significados expressos, a qualidade estética das narrativas mobilizou as emoções e a sua participação.

\section{Relações entre ideias dos textos e observações do estágio}

A última produção escrita analisada na nossa sequência didática foi o relato realizado pelos licenciandos sobre as crianças com dificuldades de aprendizagem, constatamos durante o estágio. Solicitamos que eles procurassem relacionar as ideias dos textos que discutimos com estas observações.

Todos os licenciandos relataram que estavam tendo contato com alunos a quem as professoras atribuíam dificuldades de aprendizagem. Seis equipes já estavam acompanhando de perto e conhecendo melhor as crianças. Três equipes ainda estavam tendo os primeiros contatos com elas.

Agrupamos os nove relatos dos licenciandos em quatro categorias: 1) explicita relações entre o modelo teórico de Rossato e Mitjáns Martínez (2011) e suas observações das crianças (1 relato); 2) citam alguma ideia do texto e fazem relação com suas observações (4 relatos); 3) cita alguma ideia do texto e não explicita relação com as observações (1 relato) e 4) não citam as ideias do texto (3 relatos).

Apresentamos, a seguir, resumos dos relatórios dos licenciandos que ilustram cada uma dessas categorias. Primeiro trazemos um relato que não cita as ideias do texto (Categoria 4).

O caso do aluno A., do 2‥ ano: "Temos uma pequena expectativa sobre seus atos. Ele é considerado pela professora com algum grau de autismo, nós o vemos como um aluno com altas habilidades". (O aluno A.) "Quase sempre é proativo em relação às atividades que a professora leva para sala de aula, desde a leitura e a escrita e tem uma especificidade, pois seus desenhos são muitos bons, tanto que ele cria sua própria revistinha da Turma da Mônica (no que é muito apoiado em casa). Mas por que ele seria autista segundo a visão da professora? Ele geralmente faz as atividades muito rápido, quando se trata de resultados, sempre são " 8 ou 80 ", ou seja, extremos, ora ele acerta tudo, ora erra a maioria. Ele tem aversão por várias atividades, se a professora propõe uma atividade ele vai fazer somente aquela e quaisquer que sejam as próximas serão questionadas sobre o porquê de fazer mais uma e no fim ele se recusa a fazê-la. Principalmente, quando não é bem justificada pela professora, ele se fecha, chora, grita (um dos alunos que fala mais alto na sala) principalmente quando ele se sente ameaçado (Trecho do relato de estágio - Estudantes T e G).

Apesar de não terem citado as leituras e atividades do nosso tema, consideramos interessantes algumas coincidências entre as ideias que discutimos e algumas das preocupações dos estagiários. Destacamos, no relato, a divergência dos estagiários em relação à hipótese diagnóstica da professora (autismo versus altas habilidades), a valorização de habilidades e potencialidades da criança, a preocupação com seus afetos e relacionamentos. 
Os textos que lemos trazem certas divergências entre a visão do professor da escola e os profissionais que se propõem a intervir junto as crianças com dificuldades de aprendizagem. $O$ professor de artes que ajudou Ishaan, no filme, também tinha um enfoque diferente daquele dos outros docentes da escola. $O$ aspecto da valorização do potencial de aprendizagem dos sujeitos com dificuldades de aprendizagem também estava presente nos textos discutidos e no filme que assistimos e foi ressaltado nas discussões em sala de aula.

É interessante lembrar, ainda, que João, o caso analisado no texto, e Ishaan, o protagonista do filme, tinham habilidades de desenho e a valorização dessa atividade contribuiu para a superação de suas dificuldades de aprendizagem. Além disso, a ênfase dada pelos estagiários às relações sociais e à dimensão afetiva também são aspectos considerados importantes no âmbito da teoria da subjetividade. No outro caso analisado por esta dupla de licenciandos, entretanto, a descrição se atém a aspectos do desempenho acadêmico do aluno e de suas relações com a professora em sala de aula.

Apresentamos, a seguir, o relato de outra dupla de estagiários que citam ideias do texto, mas sem explicitar relações com as suas observações (Categoria 3).

A criança C. de 10 anos, do 3‥ ano, mora com os avós e o irmão mais velho. Apresenta problemas de relacionamento e socialização, com a professora e com os colegas, não obedece à professora, é isolado, retraído, participa das brincadeiras no intervalo, mas se mete em brigas. Só faz atividade quando quer fazer, tem dificuldade para realizar as atividades, de reconhecer as letras, formar sílabas e palavras, relacionar números e quantidades. Tem algumas habilidades artísticas (desenho), facilidade de se expressar, vontade e disposição para aprender[...] "identificamos na turma do terceiro ano alguns conceitos que estão na visão de Rossato e Martínez, que são geradores das dificuldades de aprendizagem do nosso aluno pesquisado, que são: a negação do sujeito que aprende; causada pela falta de condições favorecedoras que proporcionem a produção dos sentidos subjetivos que influenciam na aprendizagem escolar, que podem, através da singularidade, contribuir para a construção de configurações subjetivas geradoras de danos, que comprometem a aprendizagem escolar deste aluno (Trecho do relato de estágio - Estudantes $M, C, V)$.

Semelhante ao anterior, notamos neste relato a preocupação dos licenciandos a respeito das relações sociais da criança com diferentes atores e em distintos contextos, bem como a valorização de suas potencialidades artísticas e motivacionais, aspectos que foram ressaltados nas nossas conversas em sala de aula, em relação aos casos de João e Ishaan. A referência ao texto é feita de forma personalizada, mas de certo modo equivocada, misturando a negação do sujeito com a produção de sentidos desfavoráveis e com as configurações geradoras de danos. Além disso, a relação das ideias com as observações fica implícita, o que nos tira a oportunidade de avaliar como elas são utilizadas.

Entre os quatro relatos que citam alguma ideia do texto e fazem relação com as observações de crianças com dificuldades de aprendizagem no estágio (Categoria 2), escolhemos o caso que transcrevemos a seguir. 
A criança B., menina de 9 anos, do 3‥ ano, que tem dificuldade de fala, apresentava comportamento agitado, gritava e não falava. A professora considerava que ela tinha alguma "especialidade", autismo. A família levou a criança ao fonoaudiólogo e ela já consegue balbuciar algumas palavras. Ela continua com dificuldades de leitura, mas consegue copiar do quadro e desenha bem [...] "Todos os sujeitos que frequentam a sala de aula são negados. Não há condições favorecedoras para que o sujeito produza coletivamente ou individualmente a aprendizagem. A professora não analisa as dificuldades de cada sujeito". Os licenciandos identificaram uma criança com deficiência visual, fato que era desconhecido da professora (Trecho do relato de estágio - Estudantes $\mathrm{A}$ e $\mathrm{M}$ ).

Novamente, notamos os licenciandos atentos, não apenas para o que falta às crianças, suas deficiências, mas para aquilo que elas apresentam de potencialidades para aprender e se desenvolver. Quando afirmam que todos os sujeitos são negados, usam a ideia de uma maneira diferente daquela que aparece no texto, referida ao sujeito individual (MITJÁNS MARTÍNEZ; GONZÁLEZ REY, 2017).

Transcrevemos, a seguir, outro relato que ilustra a Categoria 2. Novamente a negação do sujeito é a ideia trazida do texto, mas desta vez referida a uma criança específica:

Olhando o cenário que é a sala de aula, o que já pudemos perceber é que o aluno $X$ está sendo negado como sujeito que aprende, pelo simples fato de não saber os conteúdos ministrados, é deixado de lado por não conseguir acompanhar a maioria dos alunos que fazem os exercícios (Trecho do relato de estágio - Estudantes A e E).

O relato, a seguir, é um dos dois feitos pela mesma dupla de estagiários, que agrupamos na Categoria 1. Os estagiários estabeleceram relação entre as observações do estágio e o modelo teórico apresentado no texto, aproximando-se do que lhes foi solicitado fazer. Cabe ponderar que o modelo teórico não se reduz às ideias resumidas, pois guarda relações com os demais conceitos da teoria da subjetividade.

$\mathrm{O}$ caso $\mathrm{M}$, menina de 8 anos, do 2‥ ano: Entre as "dificuldades de aprendizagem escolar geradas pela negação do sujeito: a professora não tem interação com os alunos e não leva em consideração que cada aluno tem a sua singularidade, fazendo uso de práticas que não permitem ao aluno a produzir sentidos". Em relação à "ausência de condições favorecedoras à produção de sentidos subjetivos que promovam a aprendizagem escolar: a professora não auxilia no desenvolvimento dos alunos, seu contexto social não favorece o seu aprendizado". Em relação à "existência de configurações subjetivas geradoras de danos que comprometeriam a produção de sentidos subjetivos favoráveis à aprendizagem escolar: lábio leporino/ palato fendido (fator biológico)". A professora não faz reflexão sobre as práticas e não faz acompanhamento específico. Na convivência que se teve com M. é notória a sua dificuldade de entender o que falamos, a sua dificuldade de escrever. Acreditamos que seja em decorrência da anomalia apresentada e da falta de auxílio da professora (Trecho do relato de estágio - Estudantes M e M, grifos nossos).

Diferentemente dos relatos analisados anteriormente, esta dupla de licenciandos tenta usar o modelo teórico de Rossato e Mitjáns Martínez (2011) para interpretar suas observações no estágio. Usar o modelo implica analisar vários aspectos subjetivos relacionados à dificuldade, simultaneamente. Neste caso, entretanto, parece ainda haver incompreensões em relação aos conceitos. Tanto a negação do sujeito quanto a ausên- 
cia de condições para a produção de sentidos favoráveis à aprendizagem são atribuídos, exclusivamente, à forma de atuação da professora, enquanto as configurações geradoras de danos são relacionadas, diretamente, ao fator biológico.

A conclusão de que a dificuldade da criança se deve a sua anomalia e à falta de auxílio da professora nos indica que ainda está presente uma perspectiva de causação linear e direta, um determinismo biológico e um determinismo social justapostos (REGO, 1995). A maneira como a criança subjetiva essas condições sociais e biológicas não é contemplada na análise dos licenciandos.

Diante do exposto, nossos resultados permitem afirmar que ocorreram avanços, mas também dificuldades na compreensão das ideias teóricas pelos licenciandos e na relação que fizeram de tais ideias com aspectos da prática profissional, na análise da superação das dificuldades de aprendizagem.

\section{CONSIDERAÇÕES FINAIS}

Sabemos que os licenciandos tiveram pouco contato com as ideias da teoria da subjetividade, antes da sequência didática, de seis aulas, que analisamos. Temos consciência que a aprendizagem de uma teoria é um processo lento e que demanda muito esforço.

Os resultados de nossas análises mostraram, por um lado, que ocorreram avanços na compreensão dos conceitos e sua utilização pelos licenciandos para analisar a superação das dificuldades de aprendizagem. Eles entenderam a importância do diálogo para o diagnóstico e a intervenção, passaram a valorizar a singularidade do aprendiz e acreditar no seu potencial de aprendizagem. Consideraram os afetos das crianças e suas relações com diferentes atores, em distintos contextos na explicação de suas dificuldades de aprendizagem. Criticaram a padronização do ensino e a ênfase no conteúdo, defendendo atividades diferenciadas. Conseguiram fazer algumas relações das ideias dos textos com os eventos do filme e suas observações no estágio. Neste percurso, os estudos de casos ilustrativos de tais ideias (no texto, filme e estágio) mostraram-se condições relevantes para fazer avançar a compreensão dos licenciandos. Atividades como estas são recomendadas para a formação de professores (MITJÁNS MARTíNEZ; GONZÁLEZ REY, 2019).

Por outro lado, os resultados das nossas análises também indicaram dificuldades dos licenciandos para compreenderem os conceitos da teoria. Chamou nossa atenção a concepção inicial de subjetividade como algo individual, interno e oposto ao concreto/ objetivo. Além disso, destacamos a persistente visão determinista linear e unidirecional do biológico e do social sobre a dificuldade da aprendizagem e das ações do professor sobre a superação das dificuldades de aprendizagem.

Em uma pesquisa sobre a origem da singularidade humana na visão de educadores, Rego (1995) analisou produções escritas de 172 sujeitos. A autora encontrou que $14,5 \%$ da amostra atribuía a origem das características humanas a fatores internos, $20,9 \%$ a fatores externos e $50 \%$ explicavam tal origem a partir da combinação de fatores internos e externos. Na mesma direção, Tunes, Tacca e Mitjáns Martínez (2006, p. 126) afirmam que "professores e estudantes em processo de formação docente filiam-se a 
visões teóricas com forte cunho naturalista e que procuram explicar a aprendizagem de um modo reducionista". Nossos resultados confirmam essa tendência e alertam para a possibilidade de essas concepções causarem certa resistência ao aprendizado de concepções científicas que lhes sejam alternativas.

Como mencionamos anteriormente, nossa hipótese, inspirada no trabalho de Pozo e Crespo (2009), é que os licenciandos trouxeram de suas experiências anteriores teorias implícitas para explicar as ações humanas. Eles usavam estas teorias para compreender a superação das dificuldades de aprendizagem. Tais teorias diferiam epistemológica, ontológica e conceitualmente da teoria da subjetividade. Nisso residia a sua dificuldade de aprender e utilizar os conceitos da referida teoria.

A compreensão de subjetividade, sustentada inicialmente pelos licenciandos como algo individual, interno, não concreto (não objetivo), marca diferenças ontológicas significativas com a teoria da subjetividade. Nesta visão, a dificuldade de aprendizagem tende a ser pensada como algo individual e interno ao sujeito. A partir deste referencial é difícil compreender que a dificuldade de aprendizagem é, simultaneamente, individual e social, tendo uma natureza subjetiva. Ou seja, a dificuldade de aprendizagem depende da forma como o aprendiz subjetiva e é subjetivado pelos outros (professores e familiares, principalmente). Isso demanda entender que o subjetivo não é algo abstrato (um dos sentidos de subjetivo no senso comum), mas tem uma expressão no mundo concreto, como entende a teoria da subjetividade.

A visão determinista da ação humana, em um esquema de causação linear e unidirecional, que pensa a dificuldade de aprendizagem, por exemplo, como resultante da condição biológica, do contexto social ou de ambos, também vai de encontro à estrutura conceitual da teoria da subjetividade. A partir desse referencial, a dificuldade de aprendizagem tem uma origem biológica ou social que a explica e, mesmo quando se entende que existem múltiplos determinantes, biológicos, individuais e sociais, eles são tomados de maneira justaposta, apenas somados para explicar o problema. Fica complicado entender que a dificuldade de aprendizagem, mesmo quando tem origem em uma condição biológica, depende da maneira como o entorno social a subjetiva e da forma como o aprendiz produz sentidos subjetivos sobre as possibilidades e limites colocados para ele pelo social. A dificuldade de aprendizagem não chega a ser pensada como uma configuração de sentidos subjetivos, sociais e individuais, que se relacionam de forma sistêmica e recursiva.

Essa diferença, no nível dos princípios conceituais é, a nosso ver, equivalente ao que Pozo e Crespo (2009) caracterizam, nas Ciências Naturais, como a mudança de uma causalidade linear para uma interpretação de sistema de relações de interação. Os conceitos da teoria da subjetividade foram concebidos como um sistema de relações entre diferentes níveis de organização: subjetividade social, subjetividade individual, configurações de sentidos subjetivos, sentidos subjetivos. Estes níveis de organização são simultâneos e interagem recursivamente. Torna-se difícil, a partir de um referencial de causalidade linear, tomar um conceito da teoria da subjetividade sem "deformá-lo", como entender, por exemplo, que a superação das dificuldades de aprendizagem depende, diretamente, da metodologia diferenciada empregada pelo professor. 
Além das diferenças ontológicas e conceituais, os resultados de nossas análises revelam dificuldades dos licenciandos para descrever, resumidamente, o modelo teórico que explica a superação das dificuldades de aprendizagem. Também apresentaram dificuldades para analisar o filme a partir deste referencial e de pensar, a partir dele, no diagnóstico das crianças que estavam acompanhando. Em conjunto, estes resultados indicam dificuldades dos licenciandos para compreenderem a teoria da subjetividade, uma vez que também se expressam no nível epistemológico.

Mais uma vez, recorremos a Pozo e Crespo (2009) quando tratam da passagem do realismo ingênuo para o realismo interpretativo e deste para o construtivismo. Há uma tendência realista no senso comum de pensar que a realidade é tal como a percebemos (realismo ingênuo) ou que, quando necessário, a ciência nos fornece instrumentos para conhecer a realidade como ela realmente é (realismo interpretativo). A compreensão de que a ciência nos oferece modelos teóricos alternativos para pensar a realidade, mas que não são parte dela (construtivismo), é uma noção mais distante do senso comum. Nesta perspectiva, compreende-se que os conceitos não devem ser usados para explicar processos isolados, em esquemas de causalidade lineares e unidirecionais, mas para explicar relações entre processos dentro de um sistema.

Compreendemos, a partir de nosso referencial teórico, que as conquistas na construção de conhecimentos não dependem de condições específicas. O sujeito aprende em vários contextos. Assim sendo, queremos registrar que não atribuímos os avanços observados na aprendizagem dos licenciandos em nosso tema, exclusivamente às atividades que realizamos. Certamente, o que os licenciandos aprenderam em outros temas, especialmente no estágio, tem contribuições relevantes para suas aprendizagens. Nesse sentido, consideramos importante buscar maior integração com os professores supervisores de estágio e, se possível, planejar atividades conjuntas dos dois temas. A integração entre os diferentes temas é uma prática recomendada em nosso curso.

Nosso curso também se diferencia de outras licenciaturas por oferecer várias oportunidades para os licenciandos discutirem o tema da aprendizagem. Concordamos com Mitjáns Martínez e González Rey (2017, p. 160-161) quando consideram que a discussão sobre aprendizagem, apesar de presente nos currículos de formação inicial de professores, não é um tema central e que

nesses contextos se ministram conteúdos referidos, basicamente, às principais teorias de aprendizagem, sem se aprofundar adequadamente em alguma delas, nem trabalhar de forma minuciosa suas implicações e desdobramentos para o processo de ensino, questão que consideramos essencial.

Pretendemos continuar trabalhando o tema da aprendizagem na perspectiva da teoria da subjetividade, de forma aprofundada e buscando suas implicações para a prática profissional. Em futuras oportunidades planejamos realizar outras atividades e usar outros instrumentos que nos permitam conhecer melhor os licenciandos, discutir suas respostas individuais e ampliar o estudo de casos ilustrativos, usando os conceitos da teoria. Além disso, em termos da pesquisa sobre a própria prática, pretendemos ter um olhar mais atento para as trajetórias individuais. 
A formação de professores vem se constituindo como uma linha de pesquisa importante dentro da teoria da subjetividade. Nessa perspectiva, a formação é compreendida como desenvolvimento subjetivo, que não faz distinção entre o desenvolvimento profissional e o pessoal (MITJÁNS MARTÍNEZ; GONZÁLEZ REY, 2019). Nosso desafio é ensinar a teoria da subjetividade e fazer pesquisas sobre a aprendizagem de licenciandos, adotando as ferramentas conceituais, epistemológicas e metodológicas que ela nos oferece.

\section{REFERÊNCIAS}

ALVES J. M.; PARENTE A. G. L. Linguagem e conhecimento, tema da formação inicial na Licenciatura Integrada em Ciências, Matemática e Linguagem. Revista Reamec, v. 8, n. 1, p. 249-267, 2020. Disponível em: http://periodicoscientificos.ufmt.br/ojs/index.php/reamec/article/view/9861/pdf. Acesso em: 18 abr. 2020.

ANDRÉ, A. Formar o professor pesquisador para um novo desenvolvimento profissional. In: ANDRÉ, M. (org.). Práticas inovadoras na formação de professores. Campinas, SP: Papirus, 2016, p. 17-34.

BEZERRA, M. S. Dificuldades de aprendizagem e subjetividade: para além das representações hegemônicas do aprender. 2014. Dissertação (Mestrado) - Universidade de Brasília, Brasília, 2014. Disponível em: https://repositorio.unb.br/handle/10482/17772. Acesso em: 20 abr. 2020.

ESTEBAN, M. P. S. Pesquisa qualitativa em educação: fundamentos e tradições. Tradução Miguel Cabrera. Porto Alegre: AMGH, 2010.

GATTI, B. A. Educação, escola e formação de professores: políticas e impasses. Educar em Revista, 2013, n. 50, p. 51-67. Disponível em: https://www.scielo.br/pdf/er/n50/n50a05.pdf. Acesso em: 12 mar. 2019.

GATTI, B. A. Formação de professores no Brasil: características e problemas. Educação e Sociedade, v. 31, n. 113, p. 1.355-1.379, 2010. Disponível em: https://www.cedes.unicamp.br/publicacoes/edicao/77. Acesso em: 3 mar. 2019.

GATTI, B. A.; BARRETTO, E. S. de S.; ANDRE, M. E. D. A. de; ALMEIDA, P. C. A. de. Professores do Brasil: novos cenários de formação. Brasília: Unesco, 2019.

GONZÁLEZ REY, F. L. O sujeito que aprende. Desafios do desenvolvimento da aprendizagem na psicologia e na prática pedagógica. In: TACCA, M. C. V. R. (org.). Aprendizagem e trabalho pedagógico. Campinas: Alínea, 2006. p. 29-44.

GONZÁLEZ REY, F. L.; MITJÁNS MARTíNEZ, A. Subjetividade: teoria, epistemologia e método. Campinas: Alínea, 2017.

KHAN, Aamir. Como estrelas na Terra - toda criança é especial. Índia: Estúdio Aamir Khan Productions, 2007. Disponível em: https://www.youtube.com/watch?v=6rxSS46Fwk4. Acesso em: 15 jun. 2019.

KRIPKA, L.; SCHELLER, M.; BONOTTO, D. L. Pesquisa documental na pesquisa qualitativa: conceitos e caracterização. Revista de Investigaciones Unad, v. 14, n. 2, p. 55-73, 2015. Disponível em: https://hemeroteca.unad.edu.co/index.php/revista-de-investigaciones-unad/article/download/1455/1771. Acesso em: 10 maio 2020.

LÜDKE, M. O professor, seu saber e sua pesquisa. In: Educação \& Sociedade, a. XXII, n. 74, p. 77-96, abr. 2001. Disponível em: https://www.scielo.br/pdf/es/v22n74/a06v2274.pdf. Acesso em: 18 mar. 2020.

MEDEIROS, A. M. A. Análise dos processos subjetivos de aprendizagem Matemática escolar de crianças consideradas em situação de dificuldade. 2018. Tese (Doutorado) - Universidade de Brasília, Brasília, 2018. Disponível em: https://repositorio.unb.br/handle/10482/32696. Acesso em: 2 maio 2020.

MITJÁNS MARTÍNEZ, A. Epistemologia qualitativa: dificuldades, equívocos e contribuições para outras formas de pesquisa qualitativa. In: MITJÁNS MARTíNEZ, Albertina; GONZÁLEZ REY, Fernando; VALDÉS PUENTES, Roberto. Epistemologia qualitativa e teoria da subjetividade: discussões sobre educação e saúde. Uberlândia, MG: Edufu, 2019. p. 47-69.

MITJÁNS MARTÍNEZ, A.; GONZÁLEZ REY, F. L. A preparação para o exercício da profissão docente: contribuições da Teoria da Subjetividade. In: ROSSATO, Maristela; PERES, Vannúzia Leal Andrade (org.). Formação de educadores e psicólogos: contribuições e desafios da subjetividade na perspectiva cultural-histórica. Curitiba: Appris, 2019. p. 13-46.

MITJÁNS MARTÍNEZ, A.; GONZÁLEZ REY, F. L. Psicologia, educação e aprendizagem escolar: avançando na contribuição da leitura cultural-histórica. São Paulo: Cortez, 2017. 
PARENTE, A. G. L.; ALVES, J. M. A pesquisa da prática pedagógica em aulas de ciências por bolsistas do Pibid. Amazônia: Revista de Educação em Ciências e Matemática, v. 16, n. 36, p. 163-180, 2020. Disponível em: https://periodicos.ufpa.br/index.php/revistaamazonia/article/view/8264/6330. Acesso em: 17 jul. 2020.

POZO, J. I.; CRESPO, M. A. G. A aprendizagem e o ensino de ciências: do conhecimento cotidiano ao conhecimento científico. 5. ed. Porto Alegre: Artmed, 2009.

REGO, T. C. A origem da singularidade humana na visão dos educadores. Cadernos Cedes - Antropologia e Educação Interfaces do Ensino e da Pesquisa, Campinas, v. 35, p. 79-93, 1995.

ROSSATO, M.; MITJÁNS MARTÍNEZ, A. A superação das dificuldades de aprendizagem e as mudanças na subjetividade. In: TACCA, M. C. V. R. Possibilidades de aprendizagem: ações pedagógicas para alunos com dificuldade e deficiência. Campinas: Alíneas, 2011. p. 71-107.

TACCA, M. C. V. R. Estratégias pedagógicas: conceituação e desdobramentos com foco nas relações professor-aluno. In: TACCA, Maria Carmem Vileta Rosa (org.). Aprendizagem e trabalho pedagógico. Campinas, SP: Editora Alínea, 2006. p. 45-68.

TACCA, M. C. V. R. O professor investigador: criando possibilidades para novas concepções e práticas sobre ensinar e aprender. In: MITJÁNS MARTÍNEZ, Albertina; TACCA, Maria Carmen Villela Rosa. A complexidade da aprendizagem: destaque ao ensino superior. Campinas, SP: Editora Alínea, 2009. p. 53-96.

TUNES, E.; TACCA, M. C. V. R.; MITJÁNS MARTÍNEZ, A. Uma crítica às teorias clássicas da aprendizagem e sua expressão no campo educativo. Linhas Críticas, 12/22, p. 109-130, 2006. Disponível em: https://periodicos.unb.br/index.php/linhascriticas/article/view/3285. Acesso em: 13 abr. 2019. 